\title{
Contact Dermatitis: Therapeutics When Avoidance Fails
}

\author{
Esperanza Welsh ${ }^{1}$, Alina Goldenberg ${ }^{2}$, Oliverio Welsh ${ }^{3}$ and Sharon E Jacob ${ }^{4 *}$ \\ ${ }^{1}$ Dermatology Department, Centro de Especialidades Medicas, Monterrey, Mexico \\ 2 University of California, San Diego, School of Medicine; One Miramar St. \#929793, La Jolla, CA 92092, USA \\ ${ }^{3}$ Department of Dermatology, Universidad Autonoma de Nuevo Leon, Monterrey, Mexico \\ ${ }^{4}$ Department of Dermatology, Loma Linda University, Loma Linda, CA and University of California, San Diego, Division of Dermatology, La Jolla, CA 92161, USA
}

\begin{abstract}
Contact dermatitis is one of the leading reasons to visit a dermatologist. There are two main types of contact dermatitis which result from exposure to chemicals: irritant contact dermatitis, which accounts for $80 \%$ of the cases, and allergic contact dermatitis, which accounts for $15 \%$. Dermatologists must be cognizant of these diagnoses and consider appropriate and judicious use of the diagnostic patch test procedure. Once a clinically relevant allergen is diagnosed by patch testing, avoidance is the mainstay of therapy; however, medical management interventions may need to be employed in recalcitrant cases.
\end{abstract}

Keywords: Contact dermatitis; Intractable; Avoidance; Therapy

Abbreviations: ACD: Allergic Contact Dermatitis; CD: Contact Dermatitis; ICD: Irritant Contact Dermatitis; TSC: Topical Corticosteroids

\section{Allergic Contact Dermatitis Physiology}

Allergic Contact Dermatitis (ACD) involves the penetration of an allergen through the skin surface where it acts as a hapten by binding to epidermal proteins and eliciting, a delayed Type IV hypersensitivity reaction 48 to 120 hours after exposure. This immunologic response involves the activation of Th1 cells with the subsequent release of cytokines resulting in the classic inflammatory reaction.

\section{Patch Testing}

Patch testing is the main tool used for ACD diagnosis. This test involves the application of different allergens onto unaffected skin of the patients' backs. Standard screening series, such as the American Contact Dermatitis 80 Series, are available to help direct allergen selection process in adults. Additional supplemental allergens may also need to be selected based on the clinical history. The allergens are placed in chambers/wells on hypoallergenic tape and then placed on the skin. In order to effectively perform a patch test, certain guidelines must be followed. Firstly, selected test skin must not be inflamed at the time of patch testing application as this may confound the resulting response. Secondly, any excess hair should be shaved prior to application (generally a day or two before) to avoid added irritation. The patients must be advised to avoid any contact with water for 48 hours after application to decrease the risk of a false negative response, due to improper adhesion. To further optimize the patch test readability, patients are instructed on the need to avoid topical and systemic steroids, phototherapy or sun exposure, and immune modulators such as azathioprine, methotrexate, mycophenolate mofetil, cyclosporine and biologics, because these could result in a false negative response.

Forty eight hours after application, the patch tests are removed and an initial reading is done. All of the reactive areas are remarked again with a surgical marker to enable re-identification of placement during the delayed reading (72-120 $\mathrm{h}$ post-placement). This technique allows for filtering of any irritant effects which should decrease after two days, whereas the true allergic responses will likely crescendo at the later time interval. Of note, some allergens such as neomycin sulfate, sodium gold thiosulfate, and corticosteroids are reported to potentially be late reactors, and their reaction may only be seen on the delayed interval reading [1].

\section{Treatment}

Once the diagnosis of ACD is confirmed by patch testing, the mainstay of therapy is avoidance of the offending allergen. Patient education is the key to treatment adherence and symptom resolution. Patients need to understand what the substance does to their skin, where the substance is found and how to avoid it. Additionally, patients need to learn how to read labels and know that substances can be found in other products, even under different names. This educational discussion takes time and patience. Fortunately, there are two very useful tools that can be utilized to properly orient the patient as to which products he or she can safely use. The Contact Allergen Management Program (CAMP) and Contact Allergen Replacement Database (CARD) provide patients and physicians with easy-to-access lists of different products that they can use devoid of the offending agent $[2,3]$.

Although avoidance is the crucial element in trying to help patients suffering from $\mathrm{ACD}$, it sometimes fails, and exposure is inevitable; in these situations the only solution is to try to minimize as much as possible the inflammatory cascade by utilizing various medical management tools including barrier creams and emollients, topical and systemic corticosteroids, cacineurin inhibitors, antihistamines (for itch and sedation), phototherapy, steroid-sparing immune-modulators and topical and oral retinoids (Table 1).

\section{Barrier Creams and Emollients}

Barrier creams and emollients physically help decrease exposure to chemicals by decreasing the permeability and increasing hydration

*Corresponding author: Sharon E Jacob, Department of Dermatology, Loma Linda University Health, 11370 Anderson Street, Suite 2600, USA, Tel: 9095582842 ; Fax: 9095582874; E-mail: sjacob@contactderm.net

Received May 13, 2013; Accepted July 22, 2014; Published July 29, 2014

Citation: Welsh E, Goldenberg A, Welsh O, Jacob SE (2014) Contact Dermatitis: Therapeutics When Avoidance Fails. J Allergy Ther 5: 185. doi:10.4172/21556121.1000185

Copyright: (c) 2014 Welsh E, et al. This is an open-access article distributed unde the terms of the Creative Commons Attribution License, which permits unrestricted use, distribution, and reproduction in any medium, provided the original author and source are credited. 


\begin{tabular}{|l|l|}
\hline Treatment type & Dose dependent, time to onset \\
\hline Topical corticosteroids & $1-2$ weeks \\
\hline Topical retinoids & $2-4$ weeks \\
\hline Topical calcineurin inhibitors & 8 weeks \\
\hline Phototherapy or sunlight exposure & $1-3$ months \\
\hline Oral prednisone & $1-2$ weeks \\
\hline Cyclosporine & $3-6$ weeks \\
\hline Methotrexate & $6-8$ weeks \\
\hline TNF-alpha inhibitors & $1-3$ months \\
\hline Oral retinoids & $2-3$ months \\
\hline Mycophenolate mofetil & Up to 3 months \\
\hline Azathioprine & $2-6$ months \\
\hline
\end{tabular}

Table 1: ACD Treatment Duration to Effect Onset $[6,25,26]$.

of skin [4]. While some products utilize silicone and dimethicone which act as true barriers, others add natural anti-inflammatory agents such as colloidal oatmeal. Of note, petrolatums are now available with different size particles making them more cosmetically acceptable. Barrier creams or emollients should be used to decrease dryness and inflammation, and potentially minimize the need for topicals such as corticosteroids or calcineurin inhibitors.

\section{Topical Corticosteroids}

Topical Corticosteroids (TSC) are the first line of pharmacologic treatment for ACD. Their anti-inflammatory effects are multifactorial and widespread, affecting lymphocytes, monocytes, and polymorphonuclear cells [5]. Pathophysiologically, TSC's, decrease antigen-presenting function by the Langerhans'cells, and reduce synthesis and secretion of different cytokines such as interleukin-1, interleukin-2, interferon gamma, tumor necrosis factor and granulocyte-monocute-stimulating factor [5]. Lipocortin, which inhibits phospholipase A2, is induced by topical steroids leading to a marked inflammatory decline [5].

The choice of which TCS to use will depend on various factors including the location of the dermatitis, potency of the steroid, anticipated length of time of the treatment, age of the patient, and history of any type of hypersensitivity to a particular TCS. Low potency steroids are recommended for the face, genital area, and potentially occluded areas such as inframammary and axilla, where absorption is increased. Additionally, low potency TCS should be limited in their use around the eyes, due to the associated risk of glaucoma [6]. Patients should be advised to avoid rubbing their eyes if a TCS will be used on the hands. The vehicle is also of high importance as petrolatum based vehicles are greasy, but will aid in the penetration and have a moisturizing effect added, while gels, lotions and foams are better for hair bearing areas [4].

In addition to possible increased risk for glaucoma, TCS use may lead to skin atrophy, striae, and potential blockage of the HypothalamicPituitary Axis (HPA) [6]. The latter will depend on the duration of treatment, area of exposure and potency of the steroid. Especially in young children, HPA axis suppression must be monitored with AM cortisol levels and if needed a metyrapone test or insulin hypoglycemia test. Diabetes, growth retardation, bone loss, and Cushing syndrome have been reported [6].

If the patient worsens after the application of a TCS, allergy to the steroid or the vehicle should be considered. Patch testing will aid in defining whether the patient is reacting to an active or inactive ingredient in a product. If there is a reaction to the active ingredient in the steroid cream, it is important to know which structural class the active chemical belongs to and what it is likely to cross react within. TCS were classically divided into five groups based on their structure: A) hydrocortisone type, B) triamcinolone acetone type, C) betamethasone type, D1) betamethasone dipropionatetype and D2) methylprednisolone aceponate type [7]. Recently, this classification has been revised and simplified into three molecularly distinct groups arranged in the order of most allergic potential to least: 1) nonmethylated, non-halogenate (includes groups A, D2, budesonide); 2) halogenated with $\mathrm{C} 16 / \mathrm{C} 17$ cisketal/diol (includes group B); 3) halogenated C16-methylated (includes groups C and D1) [8]. Steroids within a group have the greatest potential to cross react [7].

\section{Phototherapy}

Phototherapy is an effective option for patients with intractable widespread ACD [6]. Ultraviolet light has an immunosuppressive effect and has been found to inhibit contact hypersensitivity reactions [9]. However, it has the potential side effects of acutely inducing erythema, burning or stinging and increased skin cancer risk with extended use. Due to its effectiveness, narrow band UVB at $311 \mathrm{~nm}$ has largely replaced broadband UVB. Narrowband UVB has been compared with paint-PUVA (that with topical psoralen pre-treatment) for the treatment of hand eczema with comparable results [10]. Phototherapy using UVA or PUVA consists of the administration of 8-methoxypsoralen, for which nausea is a common side-effect. PUVA has been frequently used to treat ACD of the hands, however with a risk of inducing phototoxicity $[11,12]$.

\section{Systemic Steroids}

Systemic corticosteroid therapy is a useful therapeutic alternative for those patients with an acute and severe form of contact dermatitis. It is important to try to use the minimal amount of steroids (in both duration and concentration) needed to control the disease, so as to prevent undesirable side effects. Triamcinolone $40 \mathrm{mg}$ IM can be given for acute dermatoses, however, tapered oral prednisone (at $1 \mathrm{mg} /$ $\mathrm{kg} /$ day) is more commonly utilized as it offers the ability to monitor ACD improvement or flare on tapering [6]. Of note, whereas $10 \mathrm{mg} /$ day prednisone dosed patients were found to have successful patch testing results, those on doses of $20 \mathrm{mg}$ or more per day had significant suppression of their reaction. If there is chronic contact dermatitis, it is best to use a steroid sparing immunosuppressive agent to avoid significant side effects of long-term steroid use, e.g. inhibition of HPA axis and Cushing's disease, diabetes, hypertension, peptic ulcer, osteonecrosis and osteoporosis and risk of opportunistic infections.

\section{Calcineurin Inhibitors}

Tacrolimus and pimecrolimus are other options for topical therapy. The mechanism of action of these macrolides is the inhibition of calcineurin, which blocks the ability to dephosphorylate the transcription factor NFAT-1 (Nuclear Factor of Activated T-cells). This then prevents the transcription of the gene encoding for interleukin-2, ultimately blocking T-cell activation and proliferation [13]. Additionally, topical calcineurin inhibitors block release of inflammatory cytokines and mediate the degranulation of mast cells leading to decreased pruritus as well as potential adverse effects of burning sensations [14].

Tacrolimus and pimecrolimus are approved in the US for the treatment of atopic dermatitis in adults topically in $0.1 \%$ and $0.03 \%$ formulations and in children at $0.03 \%$ as a second line therapy. Both have been used for contact dermatitis with good results [6] Macrolides have limited side effects mostly burning and stinging and 
most importantly, do not cause skin atrophy, and can be used safely on sensitive skin such as the eyelids and genitals [6]. A randomized controlled study comparing tacrolimus to placebo for the treatment of nickel allergy showed that it was superior to the vehicle [15]. A meta-analysis evaluating 17 trials comparing tacrolimus $0.03 \%$ and $0.1 \%$ ointment with TCS in pediatric patients and adult patients with atopic dermatitis concluded that tacrolimus $0.1 \%$ ointment is similar in efficacy to potent TCS [16]. The experience with atopic dermatitis may be extrapolated to patients with contact dermatitis [17].

\section{Steroid Sparing Immune Modulators}

When a patient is unable to use a systemic corticosteroid or when it will be used for a prolonged time, a steroid sparing agent is a practical approach. Cyclosporine is a calcineurin inhibitor such as tacrolimus and pimecrolimus but it is a much larger molecule. Its main mode of action is inhibiting IL-2 and interferon gamma. Patients with hand dermatitis responded to a $3 \mathrm{mg} / \mathrm{kg} / \mathrm{day}$ dose for 6 weeks with good results [18]. Dosages range from 2.5 to $5 \mathrm{mg} / \mathrm{kg} /$ day daily. Renal function and blood pressure need to be monitored closely. Complete blood count, liver enzymes and lipid profiles also need to be monitored monthly.

Mycophenolate mofetil is an inhibitor of the de novo purine biosynthesis targeting activated lymphocytes. It also inhibits dendritic cells, one of the primary antigen processing cells [6]. The drug was derived from Penicillium stoloniferum, a fermentation product [19]. The usual dose is 2 to 3 grams divided twice daily. It is started at 500 mg nightly for a week to prevent/monitor for gastrointestinal upset, then every 2-4 weeks the dose can be increased $500 \mathrm{mg}$ until the therapeutic range is reached $(\max 3 \mathrm{~g} / \mathrm{d})$. A CBC with differential, a serum chemistry panel, liver enzymes, hepatitis $B$ and $C$ panel, Purified Protein Derivative (PPD), and pregnancy test need to be checked and monitored monthly. Nausea, diarrhea and abdominal cramps are the most commonly reported adverse reactions. Additionally, the drug must be avoided in patients with childbearing potential due to risk of congenital malformations.

Methotrexate inhibits dihydrofolate reductase, a key enzyme in cell proliferation. Folic acid is the natural substrate and is chemically very similar. It can be administered orally, intravenously, subcutaneously, and intramuscularly. Dosages are generally given once a week and can be given as a single dose only or divided in three doses in 24 hours. A test dose is started at $5-10 \mathrm{mg}$ and gradually escalated at $2.5 \mathrm{mg}$ increments until there is clinical response, while trying to minimize toxicity. Folic acid is supplemented to decrease hematologic side effects such as pancytopenia on the days the methotrexate is not given. Laboratory tests are done initially and are monitored periodically and include a $\mathrm{CBC}$ with platelets, complete metabolic panel with liver enzymes, renal function, Hepatitis B and C, tuberculin test, and HIV in patients at risk. Necessity for a liver biopsy at a total dose of 3.5$4.0 \mathrm{~g}$ will depend on the disease, comorbidities, alcohol intake history, and cumulative dose [20]. Methotrexate has been reported to be helpful in chronic hand dermatitis and pompholyx [11]. Most common side effects include nausea, vomiting or diarrhea and abnormalities in liver function tests. Non-steroidal anti-inflammatory drugs should not be used with high-dose methotrexate and women must avoid becoming pregnant while taking this medication.

Azathioprine inhibits purine metabolism and thus cell division [6]. It decreases T- and B-cell function as well as antigen presentation. To select the appropriate dose, the Thiopurine Methyl Transferase enzyme (TMPT) level needs to be checked to prevent severe myelosuppression.
Patients with levels less than $6.3 \mathrm{U} / \mathrm{ml}$ should not get treated with azathioprine-it is estimated that 1 in 300 patients will be found to have insufficient TMPT levels thus barring azathioprine as a treatment option. If they are between 6.3 and $15 \mathrm{U} / \mathrm{ml}$, up to $1 \mathrm{mg} / \mathrm{kg}$ can be given daily, and at levels from 15.1 to $26.4 \mathrm{U} / \mathrm{ml}$ the dose should be given at $2-2.5 \mathrm{mg} / \mathrm{kg}$. Other laboratories to be tested include $\mathrm{CBC}$, pregnancy test, chemistry profile with liver enzymes, urine analysis and PPD. Most common side effects include myelosuppression, infections, hypersensitivity syndrome, gastrointestinal and hepatic effects. Malignancies including lymphomas and squamous cell carcinomas have been described associated with its chronic use.

Biologics are newer drugs in the armamentarium that can be of benefit when baseline therapies do not work. These drugs will inhibit different cytokines that play an important role in the inflammatory cascade that occurs in contact dermatitis. Tumor necrosis factor inhibitors include etanercept (receptor blockage), infliximab (chimeric monoclonal antibody) and adalimumab (fully humanized monoclonal antibody). Ustekinumab and IL-12 and IL-23 monoclonal antibody has been tested on 5 patients with allergic contact dermatitis with no response [21]. Further studies are needed to assess their effectiveness in $\mathrm{ACD}$.

In cases of chronic hand eczema both topical and systemic retinoids have been found effective. Bexarotene has been used topically yielding a good response [22]. Systemic retinoids such as acitretin and alitretinoin have also been reported to be safe alternatives when other modalities prove ineffective $[23,24]$. Of note, two different contraceptive measures need to be enforced if systemic retinoids are used in patients with childbearing potential.

\section{Conclusion}

ACD is a very common dermatologic condition that needs to be thought of at the office so as to provide the correct diagnosis and best treatment option for the patient. The clinical history and patch testing are the main diagnostic tools needed to elucidate the offending allergen. Patient education through careful explanation and usage of databases such as CAMP or CARD will aid the patient in knowing where the allergen is found, and how to avoid it. However, when avoidance is inevitable, pharmacologic therapy may be the only alternative. Further research of newer, steroid-sparing therapies is necessary to expand the therapeutic tool box.

\section{References}

1. Davis MD, Bhate K, Rohlinger AL, Farmer SA, Richardson DM, et al. (2008) Delayed patch test reading after 5 days: the Mayo Clinic experience. $\mathrm{J}$ Am Acad Dermatol 59: 225-233.

2. ACDS CAMP (2014) American Contact Dermatitis Society.. www.contactderm org/i4a/ams/amslogin.cfm?nextpage=/i4a/pages/index.cfm?pageid=3488

3. CARD: Contact Allergen Replacement Database. 2014. https://card.preventice. $\mathrm{com} /$

4. Rietschel RL, Fowler JF (2001) Jr. Fisher's Contact Dermatitis. (5th Edition), Williams and Wilkins, Baltimore, United States

5. Cohen DE, Heidary N (2004) Treatment of irritant and allergic contact dermatitis. Dermatol Ther 17: 334-340.

6. Jacob SE, Castanedo-Tardan MP (2007) Pharmacotherapy for allergic contact dermatitis. Expert Opin Pharmacother 8: 2757-2774.

7. Jacob SE, Steele T (2006) Corticosteroid classes: a quick reference guide including patch test substances and cross-reactivity. J Am Acad Dermatol 54: 723-727.

8. Shintani Y, Yasuda Y, Kobayashi K, Maeda A, Morita A (2008) Narrowband 
Citation: Welsh E, Goldenberg A, Welsh O, Jacob SE (2014) Contact Dermatitis: Therapeutics When Avoidance Fails. J Allergy Ther 5: 185. doi:10.4172/2155-6121.1000185

ultraviolet B radiation suppresses contact hypersensitivity. Photodermatology, Photoimmunology\&Photomedicine 24: 32-37

9. Baeck M, Goossens A (2012) New insights about delayed allergic hypersensitivity to corticosteroids. Giornaleitaliano di dermatologia e venereologia : organoufficiale, Societaitaliana di dermatologia e sifilografia 147: $65-69$

10. Sezer E, Etikan I (2007) Local narrowband UVB phototherapy vs. local PUVA in the treatment of chronic hand eczema. Photodermatology, photoimmunology and photomedicine 23: 10-14

11. Warshaw EM (2004) Therapeutic options for chronic hand dermatitis. Dermato Ther 17: 240-250.

12. Simons JR, Bohnen IJ, van der Valk PG (1997) A left-right comparison of UVB phototherapy and topical photochemotherapy in bilateral chronic hand dermatitis after 6 weeks' treatment. Clin Exp Dermatol 22: 7-10.

13. Bornhövd E, Burgdorf WH, Wollenberg A (2001) Macrolactam immuno modulators for topical treatment of inflammatory skin diseases. J Am Acad Dermatol 45: 736-743.

14. Pereira U, Boulais N, Lebonvallet N, Pennec JP, Dorange G, et al. (2010) Mechanisms of the sensory effects of tacrolimus on the skin. $\mathrm{Br} \mathrm{J}$ Dermatol 163: 70-77.

15. Belsito D, Wilson DC, Warshaw E, Fowler J, Ehrlich A, et al. (2006) A prospective randomized clinical trial of $0.1 \%$ tacrolimus ointment in a model of chronic allergic contact dermatitis. J Am Acad Dermatol 55: 40-46.

16. Svensson A, Chambers C, Gånemo A, Mitchell SA (2011) A systematic review of tacrolimus ointment compared with corticosteroids in the treatment of atopic dermatitis. Curr Med Res Opin 27: 1395-1406.
17. Fonacier LS, Aquino MR, Mucci T (2012) Current strategies in treating severe contact dermatitis in pediatric patients. Curr Allergy Asthma Rep 12: 599-606.

18. Granlund H, Erkko P, Reitamo S (1998) Long-term follow-up of eczema patients treated with cyclosporine. Acta Derm Venereol 78: 40-43.

19. Wolverton, Stephen E (2013) Comprehensive dermatologic drug therapy. (3rd Edn.), Saunders/Elsevier, Edinburgh, Scotland.

20. Dogra S, Mahajan R (2013) Systemic methotrexate therapy for psoriasis: past present and future. Clin Exp Dermatol 38: 573-588.

21. Bangsgaard N, Zachariae C, Menné T, Skov L (2011) Lack of effect of ustekinumab in treatment of allergic contact dermatitis. Contact Dermatitis 65: 227-230.

22. Hanifin JM, Stevens V, Sheth P, Breneman D (2004) Novel treatment of chronic severe hand dermatitis with bexarotene gel. Br J Dermatol 150: 545-553.

23. Capella GL, Fracchiolla C, Frigerio E, Altomare G (2004) A controlled study of comparative efficacy of oral retinoids and topical betamethasone/salicylic acid for chronic hyper keratotic palmoplantar dermatitis. J Dermatolog Trea 15: 88-93.

24. Ruzicka T, Lynde CW, Jemec GB, Diepgen T, Berth-Jones J, et al. (2008) Efficacy and safety of oral alitretinoin (9-cis retinoic acid) in patients with severe chronic hand eczema refractory to topical corticosteroids: results of a randomized, double-blind, placebo-controlled, multicentre trial. $\mathrm{Br} \mathrm{J}$ Dermatol 158: 808-817.

25. Fowler JF Jr, Maibach HI, Zirwas M, Taylor JS, Dekoven JG, et al. (2012) Effects of immunomodulatory agents on patch testing: expert opinion 2012 Dermatitis 23: 301-303.

26. Johansen JD, Frosch PJ, Lepoittevin J (2010) Contact Dermatitis, Springer. 